\title{
Scanning Electron Microscopy in High School Engineering Research
}

\author{
Michael A. Boyer ${ }^{1}$ \\ 1. Technology and Engineering Education Department, Engineering Academy, North Penn High School, \\ Lansdale, PA USA
}

Scientific research in the engineering design process is an essential skill for students to gain an in-depth understanding of the problems they are working to solve. Students quickly learn that failures are part of the design process and when given the correct context with the proper tools and support, their failures create a compelling and intrinsic motivation to persevere.

Engineering Design and Development [1], the senior capstone course of the Engineering Academy at North Penn High School, offers students the opportunity to work in teams to research and develop solutions to global issues by capitalizing from the fundamentals of science and nanotechnology. Over the past decade, the students' research has expanded from pure electrospinning experiments to applied research endeavors that incorporate the functionalization of polymer nanofibers to tackle current problems in the energy, healthcare and environmental sectors.

One of the main challenges in working at the nanoscale in a high school classroom is access to proper characterization equipment. At the onset of the program, optical characterization of the students' nanofibers was performed utilizing brightfield microscopy in the laboratory (Fig. 1) and during a single fieldtrip to Drexel University in Philadelphia, PA to utilize their Scanning Electron Microscope (Fig. 2). While the SEM at Drexel University offered the best characterization results, challenges with transportation and scheduling made it difficult for the students to review their findings, update their experiments, and reanalyze their work.

Each year, as the student research endeavors continued to increase in complexity, brightfield microscopy was no longer an effective method to characterize their experiments. Utilizing darkfield microscopy (Fig. 3) improved the fiber image quality but the nanoscale topographical features and embedded particulates could still not be effectively analyzed.

In 2007, Angstrom Scientific traveled to North Penn High School to demonstrate the Hitachi TM1000 Scanning Electron Microscope and its potential use in the laboratory for our research. The students quickly saw the benefits of having one in the lab and each year, for the next several years, Angstrom Scientific would loan us a Hitachi TM3000 SEM with elemental analysis for several weeks. As a result, the students research capabilities excelled because they could now analyze and make modifications to their research in real-time. (Fig. 4)

In 2013, Hitachi High Technologies America, visited the lab with Angstrom Scientific and witnessed first-hand the benefits of having an SEM with EDX in the lab. Since then, we have been put into a rotation to utilize the TM3030 with Elemental Analysis each year as part of the "Hitachi Change the Equation" program. Each research team is required to provide a summary of the analysis they perform. $[2]$. 
Plans are currently being developed to establish a joint international research endeavor with Dr. James Perkins [3] and his students at Queen Elizabeth's Grammar School in Faversham, England.

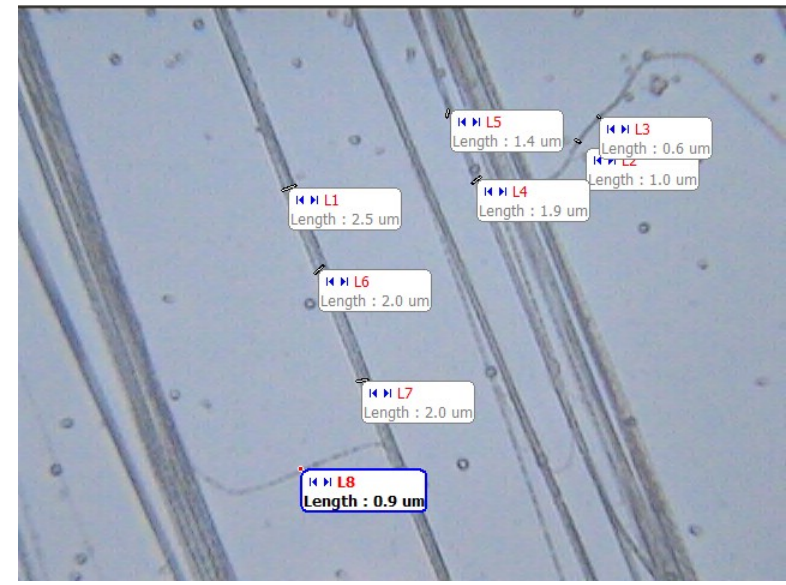

Figure 1. 2005: Brightfield microscopy: Electrospun polyethylene oxide nanofibers.

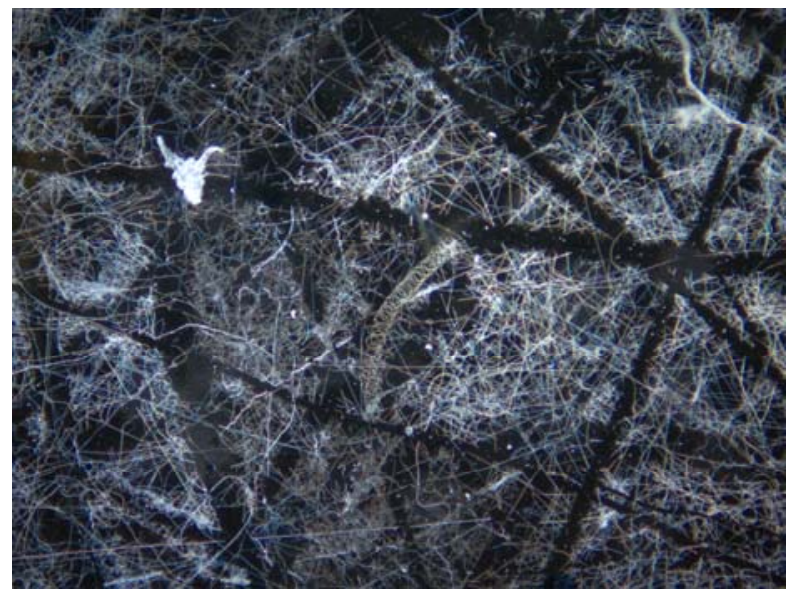

Figure 3. 2017: Darkfield microscopy: PEDOT:PSS nanofibers after an ethylene glycol bath.

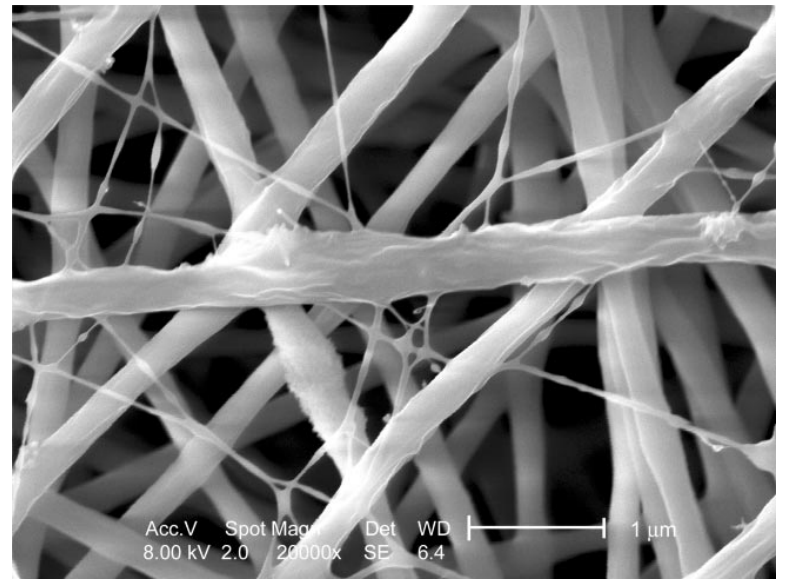

Figure 2. 2006: SEM Image Drexel University: Electrospun polyethylene oxide nanofibers.

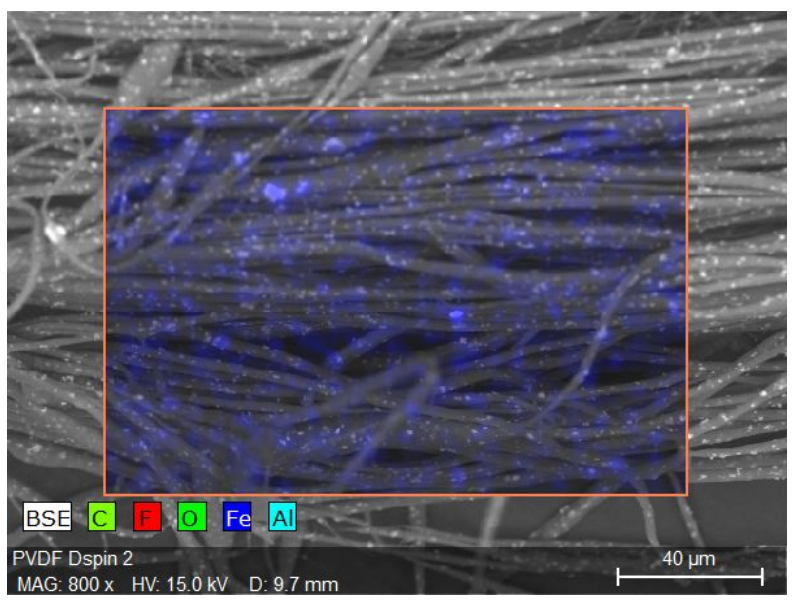

Figure 4. 2013: Hitachi TM3030: PVDF-Fe Nanofibers.

\section{References:}

[1] The Future is N.E.A.R. Nanotechnology and Engineering Research at North Penn High School. (2018). Retrieved from http://www.thefutureisnear.org

[2] STEM Education Activity Example, Lesson Plans, Inspire STEM Education. (2014). Retrieved from http://www.inspirestemeducation.us/wp-content/uploads/2014/05/SEM-Exploration-Activity.pdf

[3] Dr. James Perkins, Winston Churchill Memorial Trust.

https://www.wcmt.org.uk/users/jamesperkins2016

[4] Drexel University, Evan Slow at Angstrom Scientific, Robert Gordon at Hitachi High Technologies America, and The North Penn Educational Foundation are gratefully acknowledged for their support. 